\title{
Surgery PreTest Self-Assessment \& Review: Lillian S. Kao and Tammy Lee
}

\author{
McGraw-Hill Medical, New York, 12 edition, 2009, paperback, 373 pp., \$19.40 \\ (amazon.com)
}

\author{
Danny Rosin
}

Published online: 29 November 2009

(C) Société Internationale de Chirurgie 2009

As the 12th edition of the famous and honored PreTest series, this collection of multiple-choice questions by the two authors from the University of Texas is a success. The optimal way of learning is difficult to define and most probably depends on the type of student: Some need to hear the lecturer, others must write down every word, and there are those few who can read the textbook once and remember every detail (I envy them). However, no one doubts that repeated learning, challenging the mind to go over the learned material, and finding the correct application of the theoretical knowledge in a specific scenario are very important in consolidating knowledge. For that purpose, going over questions, struggling to get the correct answer, and reading the explanations (and sometimes even disagreeing with the "correct" answer) is a very useful technique.

While the main users of this book are those (all over the world) who prepare for the USMLE step 2 exam (the questions were prepared in a similar format and complexity), its use is certainly not limited to them. The questions help to review the material learned by both medical students and surgical trainees, covering preclinical and clinical aspects of general surgery and the surgical subspecialties. With more than 500 questions and detailed answers, each supported by a reference, this book is a great tool to prepare for exams or just help the learning process during formal studies.

While practicing clinical surgery, basic scientific knowledge of our profession tends to be forgotten or at least appears to assume secondary importance. In many residency programs, quizzes are used on a regular basis to practice the residents, refresh their basic knowledge, and "force" them to return to the textbook despite their busy schedule. This book is a wonderful source of questions for such quizzes!

As part of writing this review, as well as to satisfy my own curiosity, I have answered some hundred questions randomly selected from the various parts of this book. Many years after last using this book (a much earlier edition, I must confess), I was delighted to see that I still enjoy this kind of intellectual activity - probably even more now when there is no threatening exam waiting ahead-and I passed with a good score!

An electronic version, which is a common companion to many medical books, would have made this book even more useful, for both personal and institutional use, but even in its classical form, this small and convenient book, easy to carry and use, is still an important learning tool, even for those who consider themselves knowledgeable and experienced surgeons.

D. Rosin $(\bowtie)$

The Chaim Sheba Medical Center, 52621 Tel Hashomer, Israel

e-mail: drosin@mac.com 